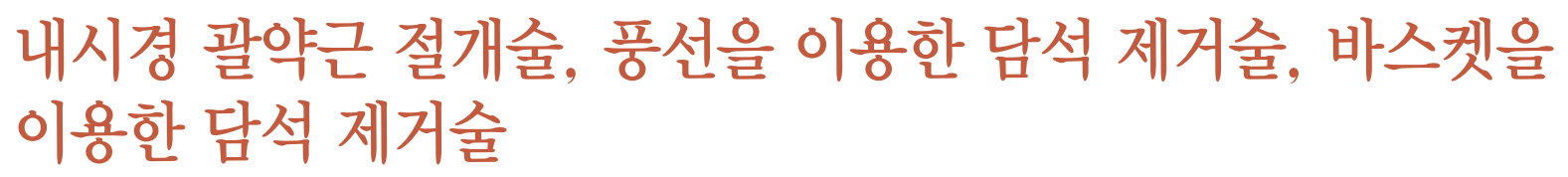

연세대학교 의과대학 강남세브란스병원 소화기내과

장성일 · 이동기

\title{
Endoscopic Sphincterotomy, Balloon Stone Extraction, and Basket Stone Extraction
}

\author{
Sung III Jang, Dong Ki Lee \\ Division of Gastroenterology, Department of Internal Medicine, Gangnam Severance Hospital, Yonsei University College of Medicine, Seoul, Korea
}

Endoscopic sphincterotomy is performed after selective cannulation to remove the gallstone. Endoscopic sphincterotomy can cause complications such as bleeding, perforation and pancreatitis. Various types of endoscopic sphincter incision method and current generators used for incisions have been developed to reduce the incidence of such complications and increase the success rate of the procedure. In addition, guidelines for the direction and extent of endoscopic sphincterotomy and incision technique are established. The method used for the removal of gallstones after the endoscopic sphincterotomy is a method using a balloon and/or a basket. This review introduces the technical methods of endoscopic sphincterotomy and discusses the clinical indications and technical methods for representative methods of effective gallstone removal.

Korean J Pancreas Biliary Tract 2019;24(4):168-174

Keywords: Choledocholithiasis, Sphincterotomy, endoscopic, Ampulla of vater, Common bile duct

\author{
Received Jun. 28, 2019 \\ Revised Aug. 3, 2019 \\ Accepted Sep. 2, 2019
}

Corresponding author : Sung III Jang

Division of Gastroenterology, Department of Internal Medicine, Gangnam Severance Hospital, Yonsei University College of Medicine, 211 Eonju-ro, Gangnam-gu, Seoul 06273, Korea

Tel. +82-2-2019-3580 Fax. +82-2-3463-3882

E-mail; aerojsi88@gmail.com

ORCID: https://orcid.org/0000-0003-4937-6167

This is an Open Access article distributed under the terms of the Creative Commons Attribution Non-Commercial License (http:/ creativecommons.org/licenses/by-nc/3.0/) which permits unrestricted non-commercial use, distribution, and reproduction in any medium, provided the original work is properly cited.

Copyright $\odot 2019$ by The Korean Journal of Pancreas and Biliary Tract

\section{서 론}

담관 담석을 제거하기 위해서는 선택적 담관삽입술(selective cannulation)이 성공한 뒤 내시경 유두괄약근 절개술을 시행하게 된다. 내시경 유두괄약근 절개술은 출혈, 천공, 췌장염 등의 합병증을 발생시킬 수 있다. 이러한 합병증의 발생을 줄이고 시술의 성공률을 높이기 위하여 다양한 형태의 내시경 괄약근 절개기와 절개를 위하여 사용되는 전류 발생기가
개발되었다. 또한 절개의 방향과 범위, 절개술에 대한 가이드라인이 정해지고 있다. 괄약근 절개 후 담석의 제거를 위하여 사용되는 방법에서 대표적으로 풍선을 이용하는 방법과 바스켓을 이용하는 방법이 있다. 내시경 괄약근 절개술의 기술적 방법을 소개하고, 효과적으로 담석을 제거할 수 있는 대표적인 방법들에 대하여 임상적 적응증과 기술적 방법에 대하여 논하고자한다. 


\section{본 론}

\section{1. 내시경 유두괄약근 절개술}

내시경 유두괄약근 절개술(endoscopic sphincterotomy)은 유두부 구멍(ampullary orifice)을 통하여 담도 안으로 전기 칼을 삽입하고 총담관과 주유두부에 있는 담관을 고주파전류 (high-frequency current)를 이용하여 절개하는 시술이다. 1973년에 내시경 유두괄약근 절개술의 동물실험이 시행되고, ${ }^{1}$ 1974년에 임상시험 결과가 보고된 후, ${ }^{2}$ 내시경 괄약근 절개술은 안전하고 효과적인 시술로 시행되고 있다. ${ }^{3,4}$ 내시경 괄약근 절개술은 담관 담석의 치료뿐만 아니라 담도의 다양한 내시경적 진단과 치료를 위하여 시행된다(Table 1).

내시경 유두괄약근 절개술은 십이지장 팽대부의 담도괄약근을 절개하는 내시경 유두부 담도괄약근 절개술 (endoscopic biliary sphincterotomy)과 췌관괄약근을 절개하는 내시경 유두부 췌관괄약근 절개술(endoscopic pancreatic sphincterotomy)로 구분된다. 그리고 담관 삽관에 성공하지 못하는 경우 시도되는 예비절개술(precut papillectomy)이 있다.

\section{2. 괄약근 절개기}

괄약근 절개기(sphincterotome)에는 끌어당기는 형(pull type), 밀어내는 형(push type), 혼합형(pull and push type)의 3 가지 형태가 있다. 끌어당기는 형은 절개선(cutting wire)을 끌어당겨서 곡선의 절개를 가능하게 하는 형태이고, 밀어내기 형은 절개선을 밀어서 절개를 가능하게 하는 형태이다.

Table 1. Indications of endoscopic sphincterotomy ${ }^{5}$

Treatment

1. Removal of bile duct stones/intrahepatic stones, and biliary drainage

2. Benign/malignant biliary stricture, biliary drainage of papillary neoplasms

3. Treatment for benign papillary stricture

4. Gallbladder drainage for acute cholecystitis

\section{Diagnosis}

1. Transpapillary bile duct biopsy

2. Biopsy for non-exposed cancer of the major papilla

3. Peroral cholangiography

4. Intraductal ultrasonography
최근에는 내시경 괄약근 절개술 시 끌어당기는 형이 주로 사용되고 있으며, 끝부분의 길이(tip length)와 칼의 길이(knife length)가 다양한 괄약근 절개기가 사용화되어 있다. 현재 사용되는 괄약근 절개기는 유도선을 위한 공간(lumen)을 가지고 있어 유도선하 안전한 괄약근 절개술이 시행되고, 피막을 가진 유도선을 이용하여 통전(passing current)에 의한 합병증이 발생하지 않도록 개발되어 사용되고 있다. 따라서 어떤 종류의 괄약근 절개기를 사용하는가에 대해서는 명확한 기준은 없으나, 안전하고 효과적인 괄약근 절개를 위하여 유도선하 괄약근 절개기(wire-guided sphincterotome)의 사용이 추천된다. ${ }^{5}$

\section{3. 절개 방향과 범위}

십이지장 바터팽대부(ampulla of Vater)는 대부분이 십이지장 제 2 부에 위치하며, 드물게 제 3 부나 다른 부위에 위치하기도 한다. 십이지장 바터팽대부를 중심으로 항문 방향에 세로주름(주름띠, longitudinal fold)이 있고 구강 방향으로 매듭주름(덮개주름, hooding fold)이 있고 그 상부의 유두지붕은 십이지장의 윤상주름(circular fold)과 수직으로 만난다.

내시경 유두괄약근 절개술은 치료 목적에 부합되면서도 시술에 관련된 합병증이 최소화되어야 한다. 이러한 결과를 얻기 위해서 가장 중요한 두 가지 요소는 절개의 방향과 절개의 상부 경계이다. 유두괄약근 절개술의 방향에 따른 출혈이나 천공의 위험도를 비교하는 연구는 없으나 절개 방향을 11 시와 12 시 사이로 하는 것이 안전하다고 추천되고 있다. 한 연구에 따르면 19개의 부검 사체에서 적출한 췌담도 조직에서 주두유두부 주변에는 98개의 동맥이 확인되었으며, 내시경 화면에서 보면 10 시에서 11 시 방향에 $10-11 \%$ 의 동맥이 존재하며, 19 개의 조직 샘플 중에서 7 개에서는 동맥이 존재하지 않았다. ${ }^{6}$ 따라서 이 방향으로 괄약근 절개를 하는 것이 출혈의 위험도를 낮출 수 있다. 결론적으로 출혈과 천공의 위험도를 낮추기 위해서는 11 시와 12 시 사이로 절개하는 것을 추천한다. ${ }^{5}$ 내시경의 위치가 절개 방향을 유지하기 어려울 경우에는 내시경을 전후로 이동하거나 공기 흡입과 주입을 반복하면서 가능한 담도 주행 방향으로 조정해야 한다. 질환의 진행이 심하거나 해부학적 변형 등으로 내시경 위치의 조작이 어려운 경우에는 절개도의 끝을 인공적으로 조작하여 원하는 방향으로 조정하는 것도 도움이 된다.

절개 범위는 소절개(small incision), 중절개(moderate 


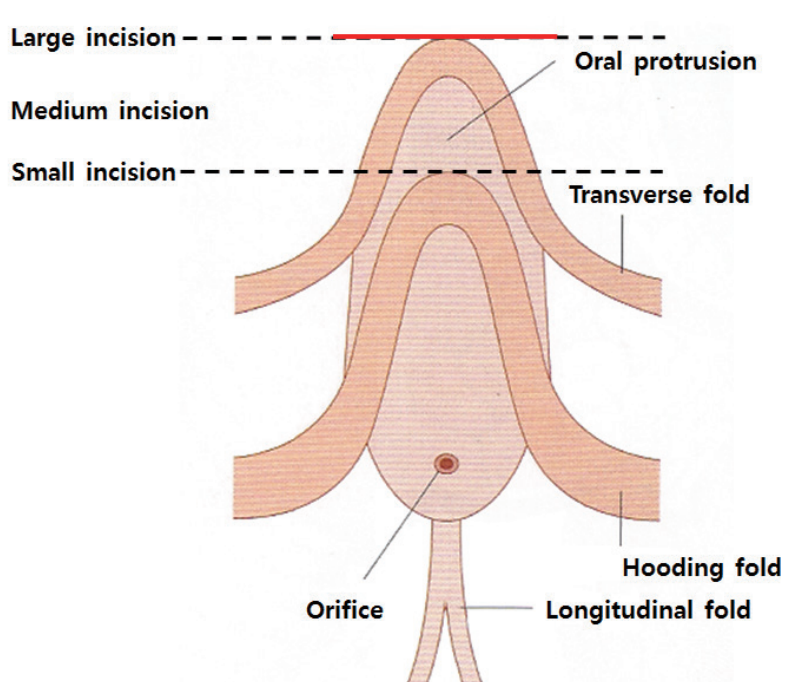

Fig. 1. Incision size of endoscopic sphincterotomy. If the incision size exceeds the superior margin of the oral protrusion, the risk of perforation increases (red line).

incision), 대절개(large incision)로 구분된다(Fig. 1). 소절개는 가로주름(transverse fold)을 넘지 않는 범위이고, 대절개는 유두부 돌출부위(papillary bulge)의 상층부까지 절개하는 경우이다. 중절개는 소절개와 대절개의 사이 절개를 의미한다. 오디 조임근(Oddi muscle) 길이는 10-30 mm이며, 유두부 내강에서 상, 중, 하층으로 구분된다. 절개 범위는 치료 대상의 질환이나 추가되는 시술의 내용에 따라 결정된다. 담관 결석을 제거하는 데 있어 담석의 크기와 관계없이 가능한 최대한 절개하여 십이지장벽내의 담관부의 괄약근을 모두 절개하는 것이 담석 제거에 효율적이다. 또한 담석 제거 후 협착이나 재발성 담석 질환의 예방에도 도움이 된다. ${ }^{8}$ 폐쇄성 황달에서 담관 배액관을 삽입하는 경우에는 상황에 따라서 소 또는 중절개만으로도 충분하다. 절개 범위에 있어 가장 중요한 부분은 천공을 예방하는 것이다. 상층부 조임근은 십이지장의 측면벽의 담관까지 확장되어 있어 이 부분까지 절개하면 천공의 위험도가 높아진다. 따라서 중층의 조임근이 존재하는 유두부 돌출부의 상층 변연부(superior margin)까지가 절개의 한계가 된다. 또한 절개 속도와 절개 철사의 긴장과 위치를 적절하게 조절하는 것이 중요하다.

\section{4. 고주파전류 발생장치}

내시경 괄약근 절개술 시에는 이미 임상에서 많이 상용화되어 있는 자동 조절 기능을 담지한 고주파전류 장비를 사용해야
한다. 고주파전류 발생장치(high-frequency generator)는 조직으로 전기 전류를 통과시키고, 이를 통하여 열과 전기적 방전을 발생시켜 조직을 절개하거나 응고 지혈시킨다. 조직 절개 시에는 고주파전류를 조직에 지속적으로 전달하고, 응고 시에는 고주파전류를 감쇠파(damped-wave)나 맥박파 (pulse-wave)로 간헐적으로 전달한다. ${ }^{9,10}$ 고주파전류를 이용한 조직절개 시 절개 시작시점에는 조직과 전극 카테터가 상대적으로 넓은 부위로 접촉하고 있어 절개 온도까지 도달하는 데 일정시간이 필요하다. 그러나 절개가 시작되면 접촉면적이 상대적으로 적어져서 절개 온도까지 도달하는 데 시간이 짧아진다. 따라서 내시경 괄약근 절개술 시 초기와 후기에 조직절개 속도에 차이가 발생한다. 이러한 차이로 인하여 내시경 괄약근 절개술 시 조직의 절개속도가 차이가 발생할 수 있어 절개 시 주의를 요하게 된다. 절개 속도가 너무 빠른 경우에는 출혈이나 천공을 유발할 수 있다. 이러한 이유로 자동조절기능을 담지한 고주파전류 장비를 많이 사용하고 있다. 본 장비는 초기에 절개에 필요한 전류량을 자동적으로 조절하고 후기에는 절개를 하지 않는 순간에는 지혈모드로 바뀌게 되어 출혈과 과도한 절개를 예방한다. ${ }^{11}$

내시경 괄약근 절개술 시 사용되는 절개 전류는 순절개(pure cut), 응고(coagulation), 융합형(cut and coagulation), 상품 전류형(proprietary currents, 절개를 자동으로 조절하는 형)으로 4 가지 종류가 있다. Endocut mode는 자동 조절기능이 있는 형으로 예상치 못한 갑작스러운 절개(zipper cut)가 드물다. 그리고 출혈, 천공, 췌장염의 발생에 있어 순절개형이나 융합형에서 차이가 없다. ${ }^{12}$ 따라서 임상에서는 출혈의 위험을 줄이고 갑작스러운 절개를 막기 위하여 Endocut형과 같이 절개를 자동으로 조절하는 형태를 선호하고 있다. 그러나 유럽소화기내시경학회 가이드라인에서는 Endocut형과 다른 절개형 사이에서 내시경 괄약근 절개술 시 발생할 수 있는 합병증에는 차이가 없기 때문에 최상의 모드에 대해서는 특정하지 않고 있다. ${ }^{13}$

\section{5. 예비절개술}

충분한 기술을 가진 췌담도 내시경 의사에서 선택적 담관 삽입의 성공률은 $90-95 \%$ 이다. ${ }^{14}$ 그러나 다양한 이유로 선택적 담관삽입술이 실패한 경우에 예비절개술(precut papillotomy)은 십이지장 유두부를 절개하여 담관 개구를 통하여 삽관술을 가능하게 한다. 예비절개술은 선형 칼(needle-knife)을 이용하는 
방법과 괄약근 절개기(sphincterotome)를 이용하는 방법이 있다. 선형 칼을 이용하는 예비절개술은 담관 유두부에서 유두부 돌출부로 절개하는 방법(upward), 유두부 돌출부에서 담관 유두부로 절개하는 방법(downward), 췌장배액관 위를 절개하는 방법이 있다. ${ }^{15,16}$ 괄약근 절개기를 이용하는 방법에는 짧고 뾰족한 괄약근 절개기를 담관 유두부에 밀착하면서 십이지장 점막을 절개하는 방법과 췌관에 괄약근 절개기를 삽입 후 췌관에서부터 유두부 돌출부 방향으로 십이지장 점막을 절개하는 방법이 있다. ${ }^{17}$

선형 칼을 이용한 전절개술은 통상의 삽관술과 비교 시 출혈이나 천공의 위험도가 증가하는 보고가 있으나 아직까지 명확한 연구가 진행되지는 않은 상태이다. 췌관을 통한 괄약근 절개술(transpancreatic sphincterotomy)은 선형 칼을 이용하는 방법에 비하여 담관 삽입 성공률이 높고 출혈의 위험도가
낮았으나, 췌장염 발생률, 천공 등과 같은 전체 합병증 발생률에는 서로 차이가 없다. ${ }^{18}$ 이러한 전절개술은 대체적으로 오랜 경험을 가진 전문가에 의하여 진행되어야 한다는 견해가 대다수이나, 대략 13 개 정도 시행 시 성공률이 $85 \%$ 를 유지하고 50 예를 시행 시 출혈이나 췌장염의 발생률이 줄어든다는 보고가 있다. ${ }^{19}$ 또한 예비절개술에 대한 경험이 증가할수록 담관삽입술의 성공률은 증가하나 합병증 발생률에는 변화가 없다는 보고가 있다. ${ }^{20}$ 따라서 일정 수준의 담관삽입술 기술을 가진 시술자에서 예비절제술에 대한 이해와 더불어 시술의 합병증 발생에 유의하면서 시술을 진행해야 한다.

\section{6. 내시경 담석 제거술}

담관 담석을 제거하는 방법에는 여러 가지가 있으나,
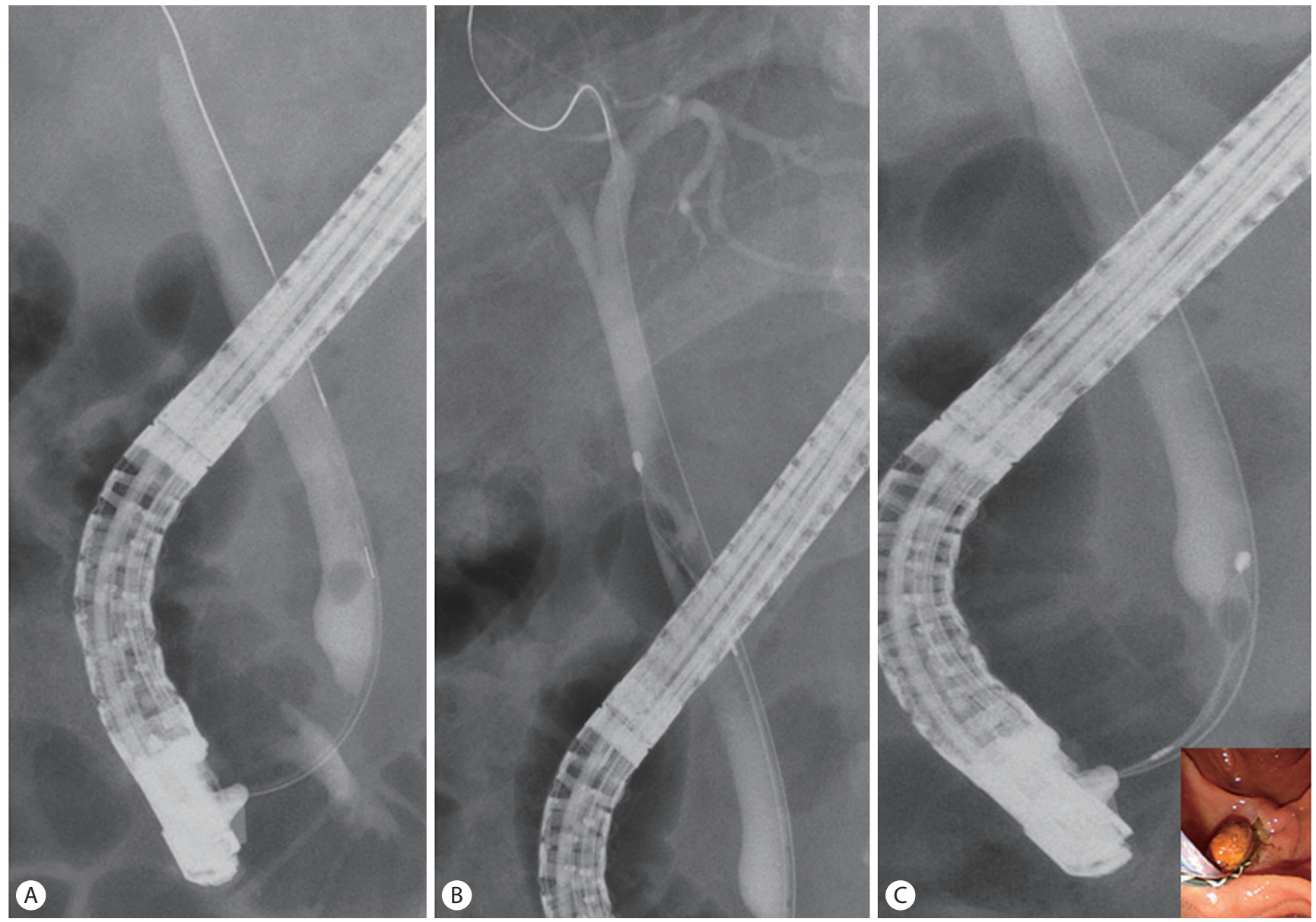

Fig. 2. Gallstone removal using a basket. (A) Confirm the size, number, and location of gallstones by administering contrast agents in the bile ducts. (B) Determine size of the basket according to the size of the gallstones and capture the gallstones into the basket. (C) Remove the captured gallstones by moving them in the direction of the ampulla to prevent them from exiting the basket. 
내시경역행담췌관조영술을 이용한 괄약근 절개술 후 담석 제거술이 1 차적인 치료법이며, 성공률이 $90 \%$ 이상이다. ${ }^{21}$ 담석에 의하여 유두부가 막히는 경우 담관의 폐쇄로 인하여 황달 및 통증, 담도염, 췌장염 등의 급성 합병증이 발생하기 때문에 담석의 내시경 치료 시 담관 담석의 완전한 제거가 필수적이다.

담석 제거를 위하여 사용되는 부속기구에는 담석 제거용 바스켓(basket)과 풍선(balloon)이 사용된다. 담석 제거용 바스켓은 견인력이 강하여 비교적 큰 담석의 제거에 유리하다. 반면에 담석 제거용 풍선은 작은 담석이나 분쇄된 담석조각들을 제거하는 데 유용하다.

\section{7. 바스켓을 이용한 담석 제거술}

담관 내 조영을 통하여 담석의 크기와 개수를 확인한 후
유두부를 통하여 바스켓을 삽입한다(Fig. 2). 바스켓을 충분히 열어서 담석을 바스켓 내로 포획한 후 바스켓을 유두부 방향으로 당겨서 담석을 제거하게 된다. 바스켓의 철선은 단일 선(monofilament wire)이나 다중 선(multifilament wire)으로 구성되고, 재질은 스테인리스(stainless)나 나이티놀(nitinol)이 사용되고 있다. 바스켓의 크기는 $45 \mathrm{~mm}$ 크기까지 다양하게 있으며 담석의 크기에 따라 시술자의 판단 하에 바스켓 크기를 정하며, 통상 $15-30 \mathrm{~mm}$ 가 흔하게 사용된다. 바스켓의 모양은 4 개의 선으로 구성된 dormia 바스켓이 기본형이며 나선형의 바스켓도 상용화되어 있다. 기존 4선 바스켓으로 포획이 어려운 작은 담석을 제거하기 위해 바스켓의 선단만 8선으로 되어 있는 flower basket (FG-401Q, Olympus, Tokyo, Japan)이나 나선형 8 선 형태의 Memory Basket ${ }^{\circledR} 8$ wire (Wilson-Cook, Bloomington, $\mathrm{IN}, \mathrm{USA}$ )도 사용된다.

바스켓을 이용한 담석 제거 시 가장 유의할 부분은 바스켓
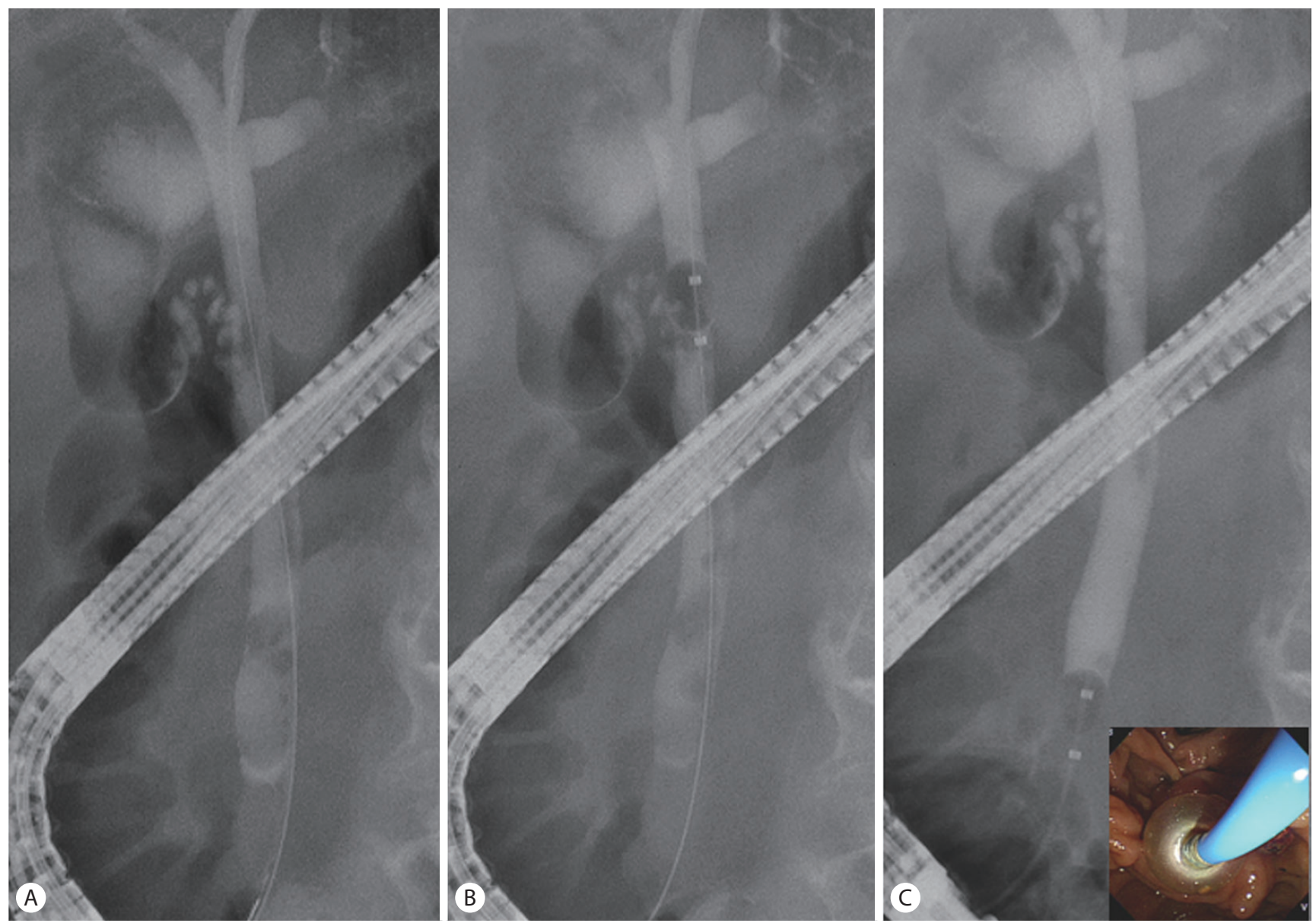

Fig. 3. Gallstone removal using a balloon. (A) Confirm the size, number, and location of gallstones by administering contrast agents in the bile ducts. (B) Determine size of the balloon according to the size of the gallstones and Inflates the balloon above the gallstones. (C) Remove the gallstones by moving the balloon in the direction of the ampulla to prevent gallstones from escaping the balloon. 
감돈이다. 바스켓 감돈은 바스켓 내로 큰 담석이 포획된 상태에서 유두부 밖으로 담석이 제거되지 않으면서 바스켓에서 담석이 풀리지 않는 현상이다. 특히 나선형 바스켓의 경우가 dormia 바스켓에 비하여 바스켓 감돈이 잘 발생하기 때문에 담석 포획 시 바스켓 감돈의 위험성에 대하여 숙지할 필요가 있다. 담석 제거술을 시행하는 과정에서 총담관 내 담석이 간내 담관으로 이동하여 간내 담관 내로 바스켓을 삽입하는 경우에는 유도선의 삽입이 가능한 바스켓을 사용하는 것이 유용하다. 그러나 간내 담관이 충분히 확장되지 않았거나 삽입된 유도선에 의하여 담석 포획이 방해받는 경우, 간내 담관 내에서 바스켓으로 담석 포획이 어려운 경우가 발생한다.

\section{8. 풍선을 이용한 담석 제거술}

선단에 풍선이 장착된 카테터를 담관에 삽입하고 부풀리지 않은 풍선을 담석의 상부로 올린 후 풍선을 팽창시켜 담관을 막아서 카테터를 유두부 방향으로 유도하여 담석을 제거한다 (Fig. 3). 풍선의 크기는 8.5-18 mm로 다양하며, 통상 $15 \mathrm{~mm}$ 크기의 풍선이 많이 사용된다. 풍선은 충분히 확장되면 담관 내에서 사각형의 모양으로 보이게 된다. 담석 제거용 풍선 카테터는 풍선을 확장시키는 공기 주입부 내강과 유도선이나 조영제의 주입이 가능한 내강이 있는 두 내강 구조(double lumen)로 되어 있다. 두 내강 구조 카테터는 조영제를 투여할 시 유도선을 제거해야 되며 추후 다시 유도선을 삽입하는 과정을 거칠 수 있어 조영제와 유도선의 주입부가 따로 구성되어 있는 세 내강 구조(triple lumen)를 가진 형태도 개발되어 있다. 세 내강 구조 풍선 카테터는 유도선이 삽입되어 있는 상태에서 조영제의 주입이 가능하며, 특히 유도선을 간내 담관에 삽입한 채 조영제를 주입할 수 있어 간내 담석의 제거에 유용하다. 그러나 두 내강 구조에 비하여 조영제의 주입부 내강이 좁아서 조영제 주입 시 저항이 더 크다.

\section{9. 바스켓 담석 제거술 vs. 풍선 담석 제거술}

총담관 담석 제거에 있어 바스켓과 풍선은 효율성과 안정성에 있어서 차이가 없다. ${ }^{22}$ 담석의 크기가 $10-11 \mathrm{~mm}$ 이하인 경우에 시행된 전향적 연구들에서 두 방식의 효율성에는 차이가 없었다. ${ }^{23,24}$ 풍선 담석 제거술은 바스켓 담석 제거술에 비해 완전제거율이 더 높을 수 있으며, ${ }^{23}$ 특히 $6 \mathrm{~mm}$ 이하의 담석을 바스켓으로 제거하는 데 10 분 이상의 시간이 걸릴 수도 있다. ${ }^{24}$
이는 작은 담석을 바스켓으로 포획하는 데 실패할 확률이 높기 때문이다. 그러나 안정성에서 두 방식은 차이가 없었다. 다만 현재 다양한 형태의 기구들이 상용화되어 있으며 이러한 기구들에 대하여 충분히 연구되지 않아 두 방식을 단순히 비교할 수는 없다. 일반적으로 담도의 해부학적 구조, 담석의 특성, 경제성 그리고 시술자의 선호도에 따라 담석 제거를 위한 효과적인 방법을 선택하게 된다. ${ }^{22}$

\section{결 론}

내시경 유두괄약근 절개술이 소개된 후 다양한 기구가 개발되고 술기가 발전하였으나, 치료 효과를 극대화하면서도 합병증 발생을 최소화하기 위해서는 기본적인 유의사항들을 숙지해야 한다. 절개 방향, 절개 범위와 더불어 절개 속도 및 절개 철사의 긴장도를 시술 시 적절하게 정하기 위해서는 이론적인 배경에 대한 이해와 실제 시술의 숙달이 필요하다. 내시경 유두괄약근 절개술 후 유두부를 통하여 담석을 제거하는 방법에는 바스켓이나 풍선을 이용하는 방법들이 있다. 담석 제거에 있어 두 방식의 유효성과 안정성은 차이가 없으나 효과적인 담석 제거를 위해서 담도의 구조, 담석의 특징을 고려하여 담석 제거 기구를 선택해야 한다.

\section{요 약}

담관 담석을 제거하기 위해서는 선택적 담관삽입술(selective cannulation)에 성공한 뒤 내시경 유두괄약근 절개술을 시행하게 된다. 내시경 유두괄약근 절개술은 출혈, 천공, 췌장염 등의 합병증을 발생시킬 수 있다. 이러한 합병증의 발생을 줄이고 시술의 성공률을 높이기 위하여 다양한 형태의 내시경 괄약근 절개기와 절개를 위해 사용되는 전류 발생기가 개발되었다. 또한 절개의 방향과 범위, 절개술에 대한 가이드라인이 정해지고 있다. 괄약근 절개 후 담석의 제거를 위해 사용되는 방법에서 대표적으로 풍선을 이용하는 방법과 바스켓을 이용하는 방법이 있다. 내시경 괄약근 절개술의 기술적 방법을 소개하고, 효과적으로 담석을 제거할 수 있는 대표적인 방법들에 대하여 임상적 적응증과 기술적 방법에 대하여 논하고자 한다.

국문 색인: 총담관결석증, 내시경 괄약근 절개, 바터팽대부, 총담관 


\section{Conflicts of Interest}

The authors have no conflicts to disclose.

\section{REFERENCES}

1. Kawai K, Aksaka Y, Hashimoto Y, Nakajima M. Preliminary report on endoscopical papillotomy. J Kyoto Pref Univ Med 1973;82:353-355.

2. Kawai K, Akasaka Y, Murakami K, Tada M, Koli Y. Endoscopic sphincterotomy of the ampulla of Vater. Gastrointest Endosc 1974;20:148 151.

3. Rabenstein T, Schneider HT, Hahn EG, Ell C. 25 years of endoscopic sphincterotomy in Erlangen: assessment of the experience in 3498 patients. Endoscopy 1998;30:A194-A201.

4. Freeman ML, Nelson DB, Sherman S, et al. Complications of endoscopic biliary sphincterotomy. N Engl J Med 1996;335:909-918.

5. Ryozawa S, Itoi T, Katanuma A, et al. Japan Gastroenterological Endoscopy Society guidelines for endoscopic sphincterotomy. Dig Endosc 2018:30:149-173.

6. Mirjalili SA, Stringer MD. The arterial supply of the major duodenal papilla and its relevance to endoscopic sphincterotomy. Endoscopy 2011:43:307-311.

7. Barraya L, Pujol Soler R, Yvergneaux JP. Technic of measured papilloinfundibulotomy, previously known as papillo-sphincterotomy. Nouv Presse Med 1973;2:2893-2896.

8. Testoni PA. Repeat sphincterotomy: does its safety depend on the interval from the initial procedure? Am J Gastroenterol 2003;98:1-3.

9. Barlow DE. Endoscopic applications of electrosurgery: a review of basic principles. Gastrointest Endosc 1982;28:73-76.

10. Morris ML, Tucker RD, Baron TH, Song LM. Electrosurgery in gastrointestinal endoscopy: principles to practice. Am J Gastroentero 2009:104:1563-1574

11. Kohler A, Maier M, Benz C, Martin WR, Farin G, Riemann JF. A new $\mathrm{HF}$ current generator with automatically controlled system (endocut mode) for endoscopic sphincterotomy--preliminary experience. Endoscopy 1998;30:351-355.

12. Perini RF, Sadurski R, Cotton PB, Patel RS, Hawes RH, Cunningham JT. Post-sphincterotomy bleeding after the introduction of microprocessor-controlled electrosurgery: does the new technology make the difference? Gastrointest Endosc 2005;61:53-57.
13. Rey JF, Beilenhoff U, Neumann CS, Dumonceau JM; European Society of Gastrointestinal Endoscopy (ESGE). European Society of Gastrointestinal Endoscopy (ESGE) guideline: the use of electrosurgical units. Endoscopy 2010;42:764-772.

14. Cotton PB. Income and outcome metrics for the objective evaluation of ERCP and alternative methods. Gastrointest Endosc 2002;56(6 Suppl):S283-S290.

15. Abu-Hamda EM, Baron TH, Simmons DT, Petersen BT. A retrospective comparison of outcomes using three different precut needle knife techniques for biliary cannulation. J Clin Gastroenterol 2005;39:717721.

16. Horiuchi A, Nakayama Y, Kajiyama M, Tanaka N. Effect of precut sphincterotomy on biliary cannulation based on the characteristics of the major duodenal papilla. Clin Gastroenterol Hepatol 2007;5:11131118.

17. Binmoeller KF, Seifert $H$, Gerke $H$, Seitz U, Portis M, Soehendra N. Papillary roof incision using the Erlangen-type pre-cut papillotome to achieve selective bile duct cannulation. Gastrointest Endosc 1996;44:689-695.

18. Pécsi D, Farkas N, Hegyi $P$, et al. Transpancreatic sphincterotomy has a higher cannulation success rate than needle-knife precut papillotomy - a meta-analysis. Endoscopy 2017;49:874-887.

19. Li JW, Ang TL, Kam JW, Kwek ABE, Teo EK. The learning curve for needle knife precut sphincterotomy revisited. United European Gastroenterol J 2017;5:1116-1122.

20. Harewood GC, Baron TH. An assessment of the learning curve for precut biliary sphincterotomy. Am J Gastroenterol 2002;97:17081712.

21. Williams EJ, Green J, Beckingham I, et al. Guidelines on the management of common bile duct stones (CBDS). Gut 2008;57:1004-1021.

22. Manes G, Paspatis G, Aabakken L, et al. Endoscopic management of common bile duct stones: European Society of Gastrointestinal Endoscopy (ESGE) guideline. Endoscopy 2019;51:472-491.

23. Ishiwatari $\mathrm{H}$, Kawakami $\mathrm{H}$, Hisai $\mathrm{H}$, et al. Balloon catheter versus basket catheter for endoscopic bile duct stone extraction: a multicenter randomized trial. Endoscopy 2016;48:350-357.

24. Ozawa N, Yasuda I, Doi S, et al. Prospective randomized study of endoscopic biliary stone extraction using either a basket or a balloon catheter: the BasketBall study. J Gastroenterol 2017;52:623-630. 